\title{
Evaluation of Homogeneous Options: Effects of Minor Actinide Exclusion from Single and Double Tier Recycle in Sodium Fast Reactors
}

R. M. Ferrer

S. Bays

M. Pope

March 2008

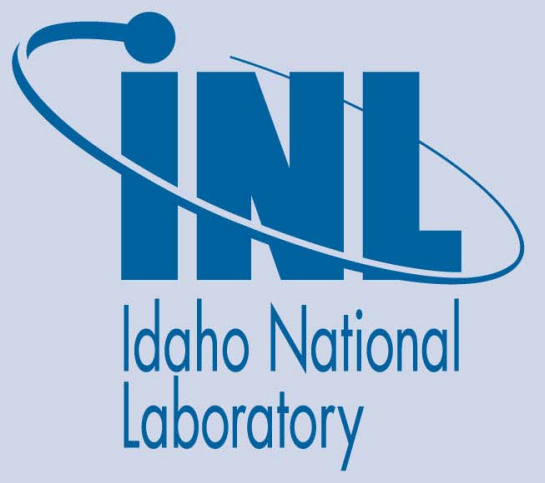

The INL is a U.S. Department of Energy National Laboratory operated by Battelle Energy Alliance 
INL/EXT-08-14034

\title{
Evaluation of Homogeneous Options: Effects of
}

\section{Minor Actinide Exclusion from Single and Double Tier Recycle in Sodium Fast Reactors}

\author{
R. M. Ferrer \\ S. Bays \\ M. Pope
}

March 2008

\begin{abstract}
Idaho National Laboratory
Idaho Falls, Idaho 83415
\end{abstract}




\section{Evaluation of Homogeneous Options: Effects of Minor Actinide Exclusion from Single and Double Tier Recycle in Sodium Fast Reactors}

INL/EXT-08-14034

March 2008

Approved by

Rodolfo M. Ferrer, Principal Author

Date

Mehdi Asgari, Reactor Physics Analysis and

Date

Design Department Manager

Kathryn McCarthy, Systems Analysis Campaign

Date

Director 


\section{ABSTRACT}

The Systems Analysis Campaign under the Global Nuclear Energy Partnership (GNEP) has requested the fuel cycle analysis group at the Idaho National Laboratory (INL) to analyze and provide isotopic data for four scenarios in which different strategies for Minor Actinides (MA) management are investigated. A 1000 MWth commercial-scale Sodium Fast Reactor (SFR) design was selected as the baseline in this scenario study. Two transuranic (TRU) conversion ratios, defined as the ratio of the amount of TRU produced over the TRU destroyed in the reactor core, along with different fuel-types were investigated.

The first case involves a single tier scenario in which the separated TRU from the Light Water Reactor (LWR) Spent Nuclear Fuel (SNF), with a 50 GWD/MTHM burnup, is assumed to be stored for 5 years, then reprocessed and fabricated during a 2 year period into Fast Reactor (FR) fuel. The second case is identical to the first, but the MA is separated from the TRU and assumed to be disposed in some other manner (stored indefinitely without further irradiation). In the latter case, the fast reactor discharged fuel is separated and only plutonium is reprocessed into fresh fast reactor fuel. It is assumed that the uranium makeup feed comes from recovered uranium.

The third case involves a two tier scenario in which the reprocessed LWR SNF plutonium is reprocessed into MOX fuel and the MA is assumed to be intermediately stored for later introduction into the SFR. After a single reactor pass with MOX, the discharged fuel (i.e.: discharged MOX-TRU) is mixed with the MA from the original LWR and sent to the SFR. In this scenario the MAs produced by the fast reactor are continuously recycled with the plutonium. Finally, the fourth case is identical to the third case, but the MA from the discharged MOX fuel is separated and the plutonium is sent to the SFR. The rest of the MA from the LWR and MOX passes are assumed to be stored indefinitely without being irradiated. Also, this scenario assumes that the MA produced by the fast reactors can be separated after each fast reactor pass and stored indefinitely without further irradiation.

The third case described above, in which the MAs are assumed to be irradiated with the plutonium in the SFR, is identical to a scenario that Argonne National Laboratory (ANL) analyzed at the requested of the US DOE-Office of Nuclear Energy [1]. In order to ensure completeness and for comparison purposes, this case was analyzed by INL and the results are summarized in this work. This specific scenario has also been expanded to include oxide fuel and $\mathrm{CR}=0.50$ design options, which where not included in previous ANL analyses. A table summarizing these four cases is shown below.

\begin{tabular}{|c|c|c|c|c|c|}
\hline Case & $\begin{array}{c}\text { Elements from } \\
\text { UOX recycled } \\
\text { directly to FR }\end{array}$ & $\begin{array}{c}\text { Elements from } \\
\text { UOX to MOX }\end{array}$ & $\begin{array}{c}\text { Elements } \\
\text { from MOX } \\
\text { or FR } \\
\text { recycled to } \\
\text { FR }\end{array}$ & $\begin{array}{c}\text { Elements } \\
\text { deliberately disposed } \\
\text { (from UOX, MOX, } \\
\text { and FR separation) }\end{array}$ & $\begin{array}{c}\text { Comparison } \\
\text { cases }\end{array}$ \\
\hline 1 & TRU & - & TRU & - & $\begin{array}{c}\text { ANL nominal 1- } \\
\text { tier case }\end{array}$ \\
\hline 2 & $\mathrm{Pu}$ & - & - & $\mathrm{Np}+\mathrm{Am}+\mathrm{Cm}$ & - \\
\hline 3 & $\mathrm{~Np}+\mathrm{Am}+\mathrm{Cm}$ & $\mathrm{Pu}$ & $\mathrm{TRU}$ & - & $\begin{array}{c}\text { ANL nominal 2- } \\
\text { tier case }\end{array}$ \\
\hline 4 & - & $\mathrm{Pu}$ & - & $\mathrm{Np}+\mathrm{Am}+\mathrm{Cm}$ & - \\
\hline
\end{tabular}


The results from these scenarios, representative core performance data at equilibrium, have been submitted to the VISION team at INL for further system analysis. The purpose of the calculations performed by the fuel cycle group for the VISION team is to ensure that the scenarios are neutronically feasible.

As expected, the higher quality plutonium feeds, which contain a larger concentration of plutonium, reduce the necessary enrichment in the plutonium-only cases relative to the 'all TRU' base cases. This is because the fissile worth of the TRU vector is degraded as MA isotopes are included in the feed. This effect is especially evident in TRU enrichment of the single tier Pu-only UOX to SFR scenario as compared to the single-tier 'all TRU' UOX to SFR case. The plutonium feed is also degraded in the two-tier MOX to SFR scenario due to the net reduction of fissile plutonium due to the MOX pass. This causes the necessary enrichment to increase as compared to the single-tier UOX to SFR scenario.

The TRU conversion ratio (CR) also changes according to the SFR makeup feed used in the simulation. Higher fuel enrichment requires higher TRU loading on a mass basis, which decreases the TRU CR due to an increase in the overall presence of the transuranics throughout the core, as compared to the scenarios in which plutonium is mostly present in the makeup (higher TRU CR)

The decay heat, gamma heating, and neutron emission data is similar for the metal and oxide fuel cases on a per TRU mass basis for equal TRU CR. On the other hand, these three parameters are all higher in the low CR (0.50) cases, as compared to the higher CR (0.75) scenarios. With respect to the reprocessing strategy, these parameters strongly depend on whether all the LWR and fast reactor SNF MAs are recycled into the fresh feed. This is due to the fact that excess MA from recovered LWR SNF, together with MA produced in the fast reactor, are assumed to be indefinitely separated and stored out-ofcore in the plutonium-only fuel cycles, thus decreasing the equilibrium charge fuel decay heat, gamma heating, and neutron emission. On the other hand, this fuel cycle generates a net amount of MA from the separated UOX, MOX, and the fast reactors discharge. Finally, the decay heat, gamma heating, and neutron emission were all observed to increase when a double tier approach is undertaken due to the net production of minor actinides that the single MOX pass creates in the fuel cycle. 


\section{DISCLAIMER}

This report was prepared as an account of work sponsored by an agency of the United States Government. Neither the United States Government nor any agency thereof, or any of their employees, makes any warranty, express or implied, or assumes any legal liability or responsibility for the accuracy, completeness, or usefulness of any information, apparatus, product, or process disclosed, or represents that its use would not infringe privately owned rights. Reference herein to any specific commercial product, process, or service by trade name, trademark, manufacturer, or otherwise, does not necessarily constitute or imply its enforcement, recommendation, or favoring by the United States Government or any agency thereof. The views and opinions of authors expressed herein do not necessarily state or reflect those of the United States Government or any agency thereof. 


\section{ACKNOWLEDGEMENTS}

The authors would like to thank Steve Piet (INL) and Michael Todosow (BNL) for their contributions. 


\section{CONTENTS}

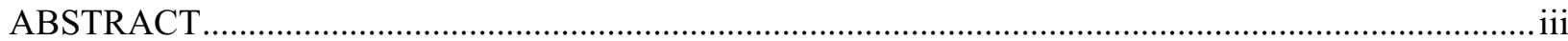

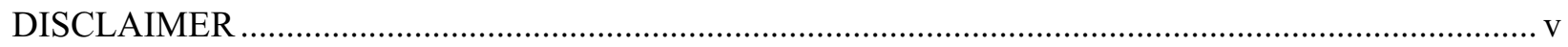

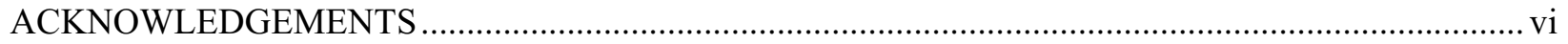

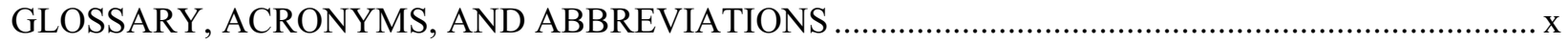

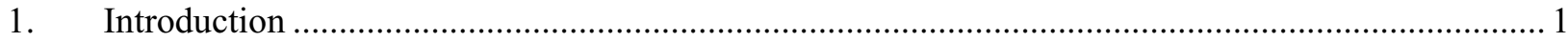

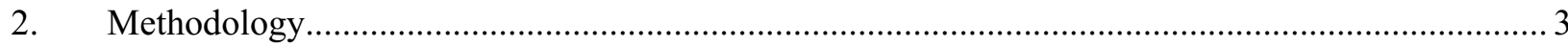

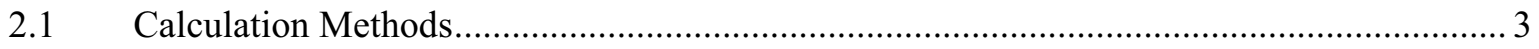

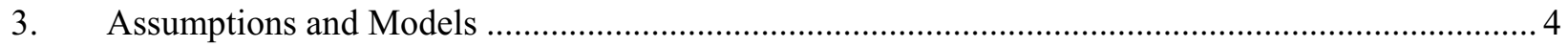

3.1 Light Water Reactor Models ................................................................................... 4

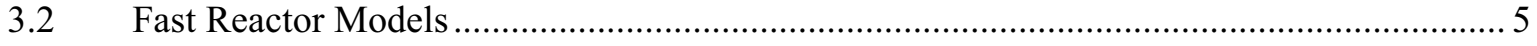

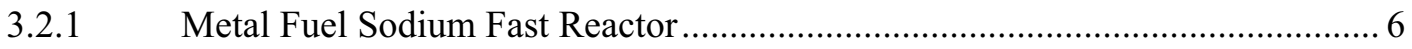

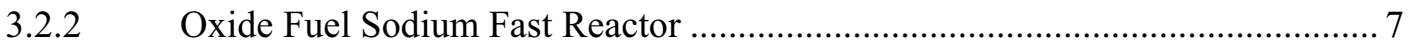

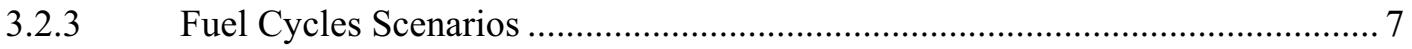

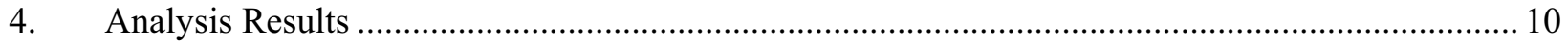

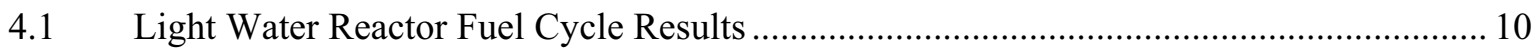

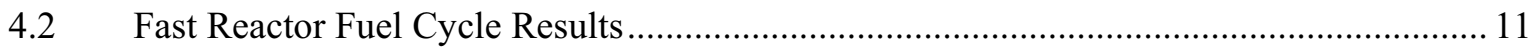

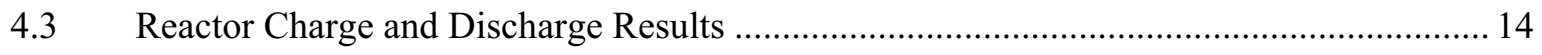

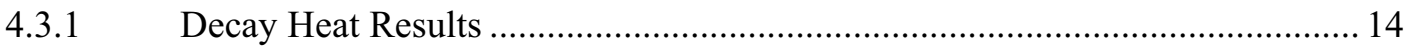

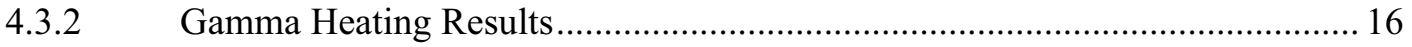

4.3.3 Neutron Emmission Results ............................................................................ 16

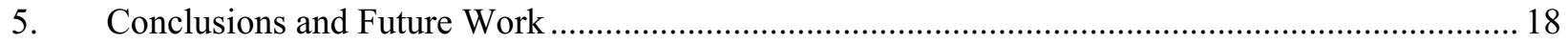

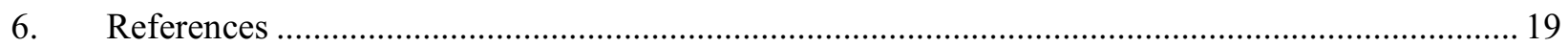




\section{FIGURES}

Figure 3-1 One Third Symmetric Radial Layout of Metal Fuel CR=0.50 SFR Design. .......................... 6

Figure 3-2 One Third Symmetric Radial Layout of Metal Fuel CR=0.75 SFR Design. .......................... 6

Figure 3-3 One Third Symmetric Radial Layout of Oxide Fuel CR=0.50, 0.75 SFR Design................... 7

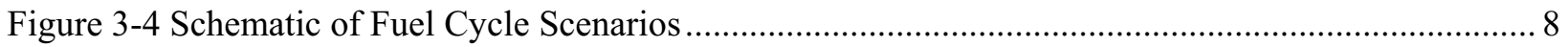

Figure 4-1 Charge Decay Heat per kg of TRU For SFR and Thermal Recycling with Multiple Scenarios.14

Figure 4-2 Charge Gamma Heating for SFR and Thermal Recycling with Multiple Scenarios................ 16

Figure 4-3 Charge Neutron Emissions for SFR and Thermal Recycling with Multiple Scenarios. ........... 17 


\section{TABLES}

Table 1-1 Summary of Fuel Cycle Scenario Parameters. ..................................................................... 1

Table 3-1 UOX and Homogeneous MOX Assembly Design Parameters. ................................................. 4

Table 3-2 Fuel Assembly Design for Metal and Oxide Fuel CR=0.50, 0.75 SFR …........................... 5

Table 3-3 External Fast Reactor TRU Isotopic Feeds in Weight Percent for Single and Double Tier

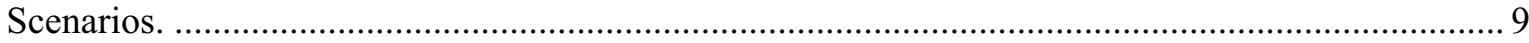

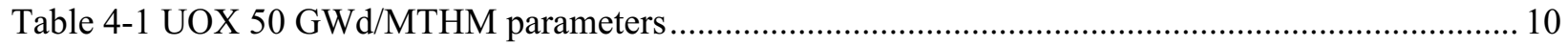

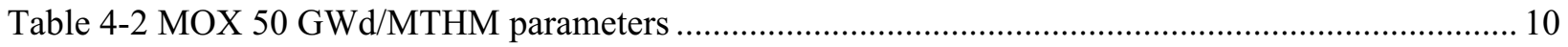

Table 4-3 Equilibrium Fuel Cycle Results for Metal SFR Design for Multiple Scenarios........................ 12

Table 4-4 Equilibrium Fuel Cycle Results for Oxide SFR Design for Multiple Scenarios...................... 13

Table 4-5 Charge and Discharge Decay Heat for Metal CR=0.50 and 0.75 SFR Design for Multiple

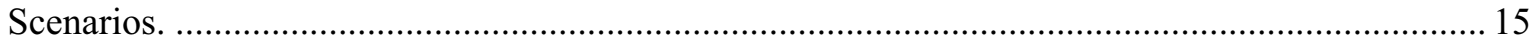

Table 4-6 Charge and Discharge Decay Heat for Oxide CR=0.50 and 0.75 SFR Design for Multiple

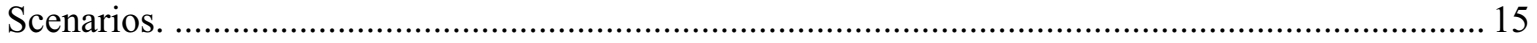




\title{
GLOSSARY, ACRONYMS, AND ABBREVIATIONS
}

\author{
ANL Argonne National Laboratory \\ DOE Department of Energy \\ GNEP Global Nuclear Energy Partnership \\ INL Idaho National Laboratory \\ LWR Light Water Reactor \\ MA Minor Actinides \\ $\mathrm{MC}^{2}-2$ Code System for Calculating Fast Neutron Spectra and Multigroup \\ Cross-Sections \\ MOX Mixed-Oxide Fuel \\ ORNL Oak Ridge National Laboratory \\ REBUS-3 Code System for Analysis of Fast Reactor Fuel Cycles \\ RSICC Radiation Safety Information Computational Center \\ SFR Sodium Fast Reactor \\ S-PRISM SuperPRISM Advanced Fast Reactor \\ SNF Spent Nuclear Fuel \\ TRU Transuranics \\ TRU CR Transuranic Conversion Ratio \\ UOX Uranium-Oxide Fuel \\ UREX Uranium Extraction Process \\ VISION Verifiable Fuel Cycle Simulation of Nuclear Fuel Cycle Dynamics
}




\section{Introduction}

The 1000 MWth Sodium Fast Reactor (SFR)-type design [2-5] was selected as the baseline in this scenario study. Two transuranic conversion ratios (TRU CR) were explored, 0.50 and 0.75 , along with metal and oxide Fast Reactor (FR) fuel options. At the request of the Systems Analysis Campaign, the fuel cycle analysis group at the Idaho National Laboratory (INL) analyzed and provided VISION isotope data for the four scenarios in which different strategies for Minor Actinides (MA) disposition were investigated. The VISION code is a computer based simulation model that allows the performance of dynamic simulations of fuel cycles to quantify infrastructure requirements and identify key trade-offs between alternatives. Since direct neutronic calculations are not performed within the model, 'recipes' for different reactor types must be provided by the fuel cycle analysis group in the form of VISIONformatted isotope data.

The first scenario involved a single tier recycling, in which the TRU from Spent Nuclear Fuel (SNF) from the Light Water Reactor (LWR) fleet is assumed to be reprocessed and fabricated into SFR fuel. The second scenario is identical to the first, but the MA from the LWR SNF is separated and assumed to be disposed in some other manner, such as long term storage (the details of a specific longterm storage are irrelevant to the calculation, since it suffices to simply assume that these MAs are not irradiated in the fuel cycle). In the latter case, the fast reactor discharged fuel is separated and only plutonium is reprocessed into fresh fast reactor fuel. The third scenario involves a two tier recycling in which the plutonium separated from the LWR SNF is reprocessed into fuel for homogeneous full-core MOX pass in an LWR and the MA is assumed to be sent to storage. After a single pass through MOX, the discharged fuel is mixed with the MA from the original LWR and sent to the SFR. In this scenario, the MAs produced by the fast reactor are continuously recycled with the plutonium. Finally, the fourth case is identical to the third case, but the MA from the discharged MOX fuel is separated and sent to storage and the remaining plutonium is sent to the fast reactor. Also, in this scenario, the MAs produced by the fast reactor are separated from plutonium after each reactor pass and sent to storage. For all four of these cases it is assumed that the makeup feed for the uranium is drawn from reprocessed uranium reserves. A table summarizing the cases is shown below.

Table 1-1 Summary of Fuel Cycle Scenario Parameters.

\begin{tabular}{|c|c|c|c|c|c|}
\hline Case & $\begin{array}{c}\text { Elements from } \\
\text { UOX recycled } \\
\text { directly to FR }\end{array}$ & $\begin{array}{c}\text { Elements from } \\
\text { UOX to MOX }\end{array}$ & $\begin{array}{c}\text { Elements } \\
\text { from MOX } \\
\text { or FR } \\
\text { recycled to } \\
\text { FR }\end{array}$ & $\begin{array}{c}\text { Elements } \\
\text { deliberately disposed } \\
\text { (from UOX, MOX, } \\
\text { and FR separation) }\end{array}$ & $\begin{array}{c}\text { Comparison } \\
\text { cases }\end{array}$ \\
\hline 1 & TRU & - & TRU & - & $\begin{array}{c}\text { ANL nominal 1- } \\
\text { tier case }\end{array}$ \\
\hline 2 & $\mathrm{Pu}$ & - & - & $\mathrm{Np}+\mathrm{Am}+\mathrm{Cm}$ & - \\
\hline 3 & $\mathrm{~Np}+\mathrm{Am}+\mathrm{Cm}$ & $\mathrm{Pu}$ & $\mathrm{TRU}$ & - & $\begin{array}{c}\text { ANL nominal 2- } \\
\text { tier case }\end{array}$ \\
\hline 4 & - & $\mathrm{Pu}$ & - & $\mathrm{Np}+\mathrm{Am}+\mathrm{Cm}$ & - \\
\hline
\end{tabular}

Representative core performance data at equilibrium has been submitted to the VISION team at INL for further understanding as to how these four scenarios affect the fuel cycle system as a whole. The 
purpose of these calculations is to ensure that the scenarios are neutronically feasible. In addition to providing 'recipes' for each scenario, important fuel handling data is collected, such as equilibrium charge decay heat, gamma heating, and neutron emission, along with the decay heat per subassembly as a function of cooling time. While no conclusions regarding the four scenarios are drawn in this report, from the perspective of which scenario option is optimal with regards to certain parameters and metrics, the assumptions and approaches used in this analysis are outlined and data from the results presented and discussed. 


\section{Methodology}

\subsection{Calculation Methods}

\section{Light Water Reactor Calculations}

The calculations were performed using the TRITON code that is part of the SCALE 5.1 package [6]. The TRITON code [7] acts as a link between the transport code NEWT and the depletion code ORIGEN$\mathrm{S}$ [8]. The calculations thus track all isotopes available in ORIGEN-S, which numbers in the thousands. The results for these isotopes are then processed according the requirements of the VISION team to a subset of 81 isotopes.

\section{Fast Reactor Calculations}

The fast reactor codes $\mathrm{MC}^{2}-2$ [9] and REBUS-3 [10] were used to generate multi-group fast spectrum cross-sections and to perform fuel cycle calculations. The $\mathrm{MC}^{2}-2$ code was used to generate 33 energygroup cross section sets (group constants) for each of the fuel enrichment zones, reflectors and shields. Starting with an ultra-fine group ENDF/B-V cross section library, $\mathrm{MC}^{2}-2$ creates collapsed cross section sets by performing a critical buckling search. These cross section sets are subsequently concatenated into a single data file so that they may be used by the fuel cycle code REBUS-3 to perform an enrichment search for an equilibrated fuel cycle given user-defined constraints, such as burnup limit.

The REBUS-3 nodal diffusion option in hexagonal-z geometry was used to perform the flux | calculations. In our fuel cycle model $_{2}$ individual fuel assemblies within a region (enrichment region) are homogenized utilizing representative neutron spectra. Therefore, independent batches of fuel are tracked within the external fuel cycle but not explicitly spatially represented in the physics calculation. Furthermore, the constraints in the equilibrium calculations involved a search of the specific fresh fuel charge enrichment given a peak fast fluence limit. An automated scripting system is used to re-calculate the cross-sections for each enrichment zone based on that zone's fuel inventory at equilibrium. This ensures that the group constants correspond to the equilibrium case (since the initial cross section set is based only on an estimate of the actual TRU enrichment). Since REBUS-3 only deals with the closed portion of the fuel cycle, the externally supplied feed is made sufficiently large to provide the reprocessing with enough heavy metal to constitute the next batch of fresh fuel.

\section{Decay Heat, Gamma Heating, and Neutron Emission}

Finally, the SCALE 5.1 code package was used to generate LWR SNF feeds for the SFR. The depletion code ORIGEN-S was used to predict the concentration of isotopes after cooling and storage. SCALE 5.1 was also used to calculate the decay heat, gamma heating, and neutron emission heat for the beginning-of-equilibrium cycle (BOEC) mass charge reported by REBUS-3 and was normalized on a per $\mathrm{kg}$-TRU basis. Furthermore, ORIGEN-S was used to perform a decay heat calculation of the discharge fuel from the moment it exits the core out to 20 years in the future. This latter calculation was normalized on a assembly level. 


\section{Assumptions and Models}

This section presents brief discussion of the LWR and SFR models and their corresponding external fuel cycle. Detailed thermal-hydraulics and material considerations, such as linear power limits and thermal conductivity models for the metal and oxide fuels, are discussed in details in previous reports [11]. The methodology applied to the variation of the conversion ratio involved a reduction in pin diameter, which effectively reduces the fuel volume fraction. This causes the TRU enrichment to increase and consequently the conversion ratio to decrease for the same fuel cycle. Once again, detailed descriptions of this process and its effects on the thermal performance of the assembly design are available in other reports [11].

\subsection{Light Water Reactor Models}

The LWR core data and calculation parameters assumed for the Tier 0 and Tier 1 LWR calculations are summarized in Table 3-1. It is assumed in all four scenarios that the commercial sector is composed of LWRs using uranium oxide (UOX) fuel. For the purpose of this study it is also assumed that data for pressured water reactors (PWRs) is a good representative of the commercial fleet; in actuality only 2/3 of LWRs in the U.S. are PWRs. The data are for a PWR with 193 assemblies operating at 3000 MWth containing bundles with 264 fuel pins with an active fuel height of $3.6576 \mathrm{~m}$, one instrument channel and 24 guide tubes. The specific power of the core is assumed to be $33.69 \mathrm{~W} / \mathrm{g}$ for 50 GWD/MTHM burnup in both Tier 0 calculations. The specific power for the Tier 1 MOX was evaluated to be $33.499 \mathrm{~W} / \mathrm{g}$ for $50 \mathrm{GWD} / \mathrm{MTHM}$ burnup. Reactivity balance and mass flow data for the LWR UOX and MOX cores were obtained using the linear reactivity model (LRM) and unit assembly model assuming core leakage of $3.5 \%$; a three-batch core is assumed.

Table 3-1 UOX and Homogeneous MOX Assembly Design Parameters.

\begin{tabular}{|c|c|c|}
\hline & $\begin{array}{l}\text { Tier 0 } \\
\text { (Both Scenarios) }\end{array}$ & $\begin{array}{l}\text { Tier } 1 \\
\text { (Second Scenario) }\end{array}$ \\
\hline Assembly size & $17 \times 17$ & $17 \times 17$ \\
\hline Number of fuel pins & $264 \mathrm{UOX}$ & $264 \mathrm{MOX}$ \\
\hline Number of guide tubes (GT) & 24 & 24 \\
\hline Number of instrumentation tubes (IT) & 1 & 1 \\
\hline Fuel rod pitch $(\mathrm{cm})$ & 1.26 & 1.26 \\
\hline Inter-assembly gap (cm) & 0.08 & 0.08 \\
\hline Fuel pellet radius $(\mathrm{cm})$ & 0.4096 & 0.4096 \\
\hline Clad inner radius $(\mathrm{cm})$ & 0.4178 & 0.4178 \\
\hline Clad outer radius $(\mathrm{cm})$ & 0.4750 & 0.4750 \\
\hline Smeared fuel density $\left(\mathrm{g} / \mathrm{cm}^{3}\right)$ & 9.88 & 9.94 \\
\hline Zr clad density $\left(\mathrm{g} / \mathrm{cm}^{3}\right)$ & 6.55 & 6.55 \\
\hline Coolant density $\left(\mathrm{g} / \mathrm{cm}^{3}\right)$ & 0.7116 & 0.7116 \\
\hline GT/IT inner radius $(\mathrm{cm})$ & 0.5715 & 0.5715 \\
\hline GT/IT outer radius $(\mathrm{cm})$ & 0.6121 & 0.6121 \\
\hline Specific power density (MW/MTHM) $)^{1)}$ & 33.69 & 33.499 \\
\hline Fuel temperature $(\mathrm{K})$ & 900 & 900 \\
\hline Cladding temperature $(\mathrm{K})$ & 630 & 630 \\
\hline Bulk coolant temperature $(\mathrm{K})$ & 580 & 580 \\
\hline
\end{tabular}




\subsection{Fast Reactor Models}

The strategy followed in the reduction of the conversion ratio of the SFR models from the original S-PRISM designs was to reduce the fuel pin diameter in the fuel assemblies.

The fuel assembly cold dimensions, along with the fuel pin design and volume fractions for the reference metal and oxide SFRs, are listed in Table 3-2. The original S-PRISM assembly design had 271 pins per assembly, while the assembly designs for the metal and oxide $\mathrm{CR}=0.50 \mathrm{SFR}$ has 324 pins per assembly. The reduced thermal conductivity and/or fuel solidus temperature of higher TRU enriched fuel pins required a larger number of pins per assembly in order to reduce the average linear power to an acceptable limit. The shrinking of the fuel pin diameter also entails using spacer grids instead of wire wrap in the assembly design, thus the difference between the $\mathrm{CR}=0.50$ (higher TRU enrichment) and 0.75 (lower TRU enrichment). Also worth noting is the axial heights of the designs. The axial dimension of oxide core is $35 \%$ taller than the metal core. This is due to the lower mass density of oxide fuel and thus the need to increase the fuel volume in order to accommodate comparable amounts of TRU to the metal fuel case. The detailed design and geometry of the control rod mechanism, reflector, and shield can be found in other reports. It suffices to say that these are modeled as homogenous regions and are very similar to those proposed for the S-PRISM design [2].

Table 3-2 Fuel Assembly Design for Metal and Oxide Fuel CR=0.50, 0.75 SFR.

\begin{tabular}{|c|c|c|c|c|}
\hline & \multicolumn{2}{|c|}{ Metal } & \multicolumn{2}{|c|}{ Oxide } \\
\hline & $\mathrm{CR}=0.50$ & $\mathrm{CR}=0.75$ & $\mathrm{CR}=0.50$ & $\mathrm{CR}=0.75$ \\
\hline Assembly pitch, cm & 16.142 & 16.142 & 16.142 & 16.142 \\
\hline $\begin{array}{c}\text { Inter-assembly gap, } \\
\mathrm{cm}\end{array}$ & 0.432 & 0.432 & 0.432 & 0.432 \\
\hline $\begin{array}{c}\text { Duct outside flat-to- } \\
\text { flat, cm }\end{array}$ & 15.710 & 15.710 & 15.710 & 15.710 \\
\hline Duct material & HT9 & HT9 & HT9 & HT9 \\
\hline Duct thickness & 0.394 & 0.394 & 0.394 & 0.394 \\
\hline $\begin{array}{c}\text { Fuel Pins per } \\
\text { Assembly }\end{array}$ & 324 & 271 & 324 & 271 \\
\hline Spacer Type & Grid & Wire & Grid & Wire \\
\hline Bond & $\mathrm{Na}$ & $\mathrm{Na}$ & $\mathrm{He}$ & $\mathrm{He}$ \\
\hline Core Height, $\mathrm{cm}$ & 101.60 & 101.60 & 137.16 & 137.16 \\
\hline Plenum Height, $\mathrm{cm}$ & 191.14 & 191.14 & 170.82 & 170.82 \\
\hline $\begin{array}{l}\text { Overall Pin Length, } \\
\mathrm{cm}\end{array}$ & 407.04 & 407.04 & 422.28 & 422.28 \\
\hline $\begin{array}{c}\text { Fuel Smeared/ } \\
\text { Fabrication Density, } \\
\% \text { TD }\end{array}$ & $75 / 100$ & $75 / 100$ & $85 / 89.4$ & $85 / 89.4$ \\
\hline Pin Diameter, $\mathrm{cm}$ & 0.623 & 0.755 & 0.658 & 0.808 \\
\hline $\begin{array}{c}\text { Cladding Thickness, } \\
\mathrm{cm}\end{array}$ & 0.0559 & 0.0559 & 0.0635 & 0.0635 \\
\hline $\begin{array}{l}\text { Wire Wrap Diameter, } \\
\text { cm }\end{array}$ & N/A & 0.1329 & $\mathrm{~N} / \mathrm{A}$ & 0.0797 \\
\hline $\begin{array}{c}\text { Pin Pitch-to-diameter } \\
\text { Ratio }\end{array}$ & 1.293 & 1.176 & 1.224 & 1.099 \\
\hline \multicolumn{5}{|l|}{ Vol. Fractions, \%: } \\
\hline Fuel & 22.08 & 29.30 & 30.22 & 41.65 \\
\hline Bond & 7.36 & 9.77 & 1.56 & 2.16 \\
\hline Structure & 26.41 & 25.68 & 29.22 & 27.71 \\
\hline Coolant & 44.15 & 35.25 & 39.00 & 28.48 \\
\hline
\end{tabular}




\subsubsection{Metal Fuel Sodium Fast Reactor}

The radial layout of the metal $\mathrm{CR}=0.50 \mathrm{SFR}$ core consists of three driver fuel regions; the inner, middle, and outer core. A schematic of this layout is shown below in Figure 3-1. The inner core consists of four rows containing a total of 42 assemblies. The middle core consists of two rows containing a total of 66 assemblies with a charge TRU enrichment of 1.25 times that of the inner core. The outer core consists of a single row containing 36 assemblies with a charge TRU enrichment of 1.50 times that of the inner core. Such an enrichment splitting allows for the flattening of the power distribution. The reflector and shield regions of the core correspond to the last three rows of the core. While the ultimate shutdown and primary control rods are shown in the schematic, these were modeled as fully withdrawn.

The radial layout of the metal $\mathrm{CR}=0.75 \mathrm{SFR}$ is slightly different than the $\mathrm{CR}=0.50$ design. The inner core region is decreased by converting the outer row into a middle core region row. The outer core region is increased by converting the second middle core row into an outer core row. Other than this change in enrichment splitting, the rest of the core layout remains identical. A schematic of this layout is shown below in Figure 3-2.

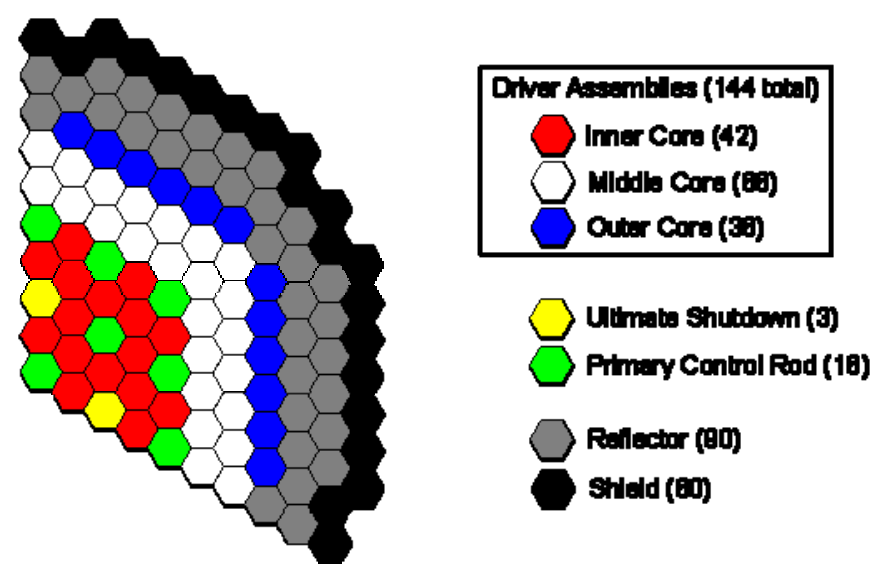

Figure 3-1 One Third Symmetric Radial Layout of Metal Fuel CR=0.50 SFR Design.
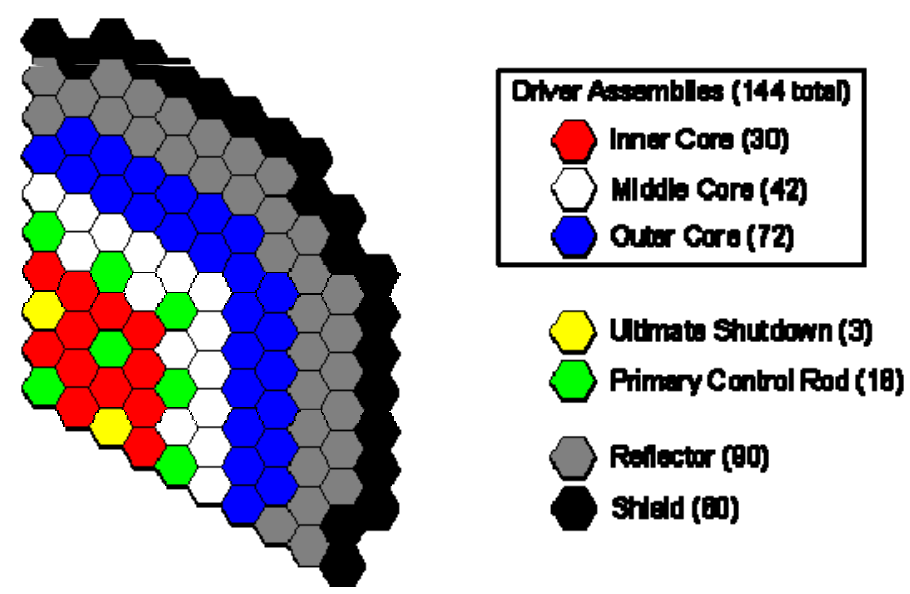

Figure 3-2 One Third Symmetric Radial Layout of Metal Fuel CR=0.75 SFR Design. 


\subsubsection{Oxide Fuel Sodium Fast Reactor}

The radial layout of the oxide core, similar to the metal SFR, consists of three driver fuel regions; the inner, middle, and outer core. A schematic of this layout is shown below in Figure 3-3. The inner core consists of five rows containing a total of 72 assemblies while the middle core consists of one row containing a total of 36 assemblies with a charge TRU enrichment of 1.25 times that of the inner core. Finally, the outer core consists of a single row containing 36 assemblies with a charge TRU enrichment of 1.50 times that of the inner core. The reflector, shield, the ultimate shutdown and primary control rods were modeled as fully withdrawn. Unlike in the case of the metal SFR, the core layout remains identical for both $\mathrm{CR}=0.50$ and $\mathrm{CR}=0.75$ designs.

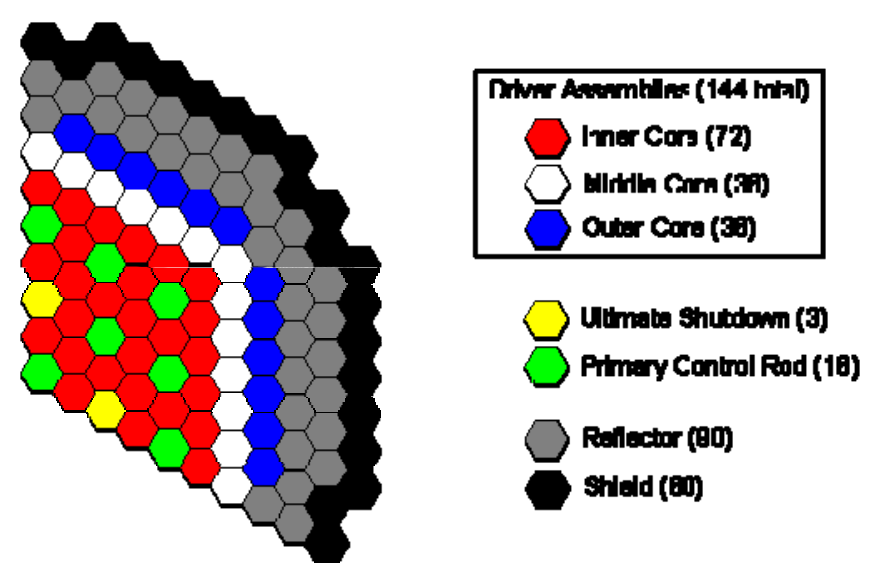

Figure 3-3 One Third Symmetric Radial Layout of Oxide Fuel CR=0.50, 0.75 SFR Design.

\subsubsection{Fuel Cycles Scenarios}

A total of four fuel cycle scenarios were analyzed in this study. In all four scenarios it is assumed that LWR SNF is cooled for a period of five years post-irradiation. In two of these scenarios the recovered TRU is used either to fabricate SFR fuel or partitioned into Pu and the MAs, in which case only $\mathrm{Pu}$ is used in the fabrication of SFR fuel and the MA is assumed to be stored out-of-core. In either case the recovered TRU Pu is decayed for an extra period of two years to simulate the fabrication period.

In the two other scenarios the recovered TRU is partitioned to separate the plutonium $(\mathrm{Pu})$ from the minor actinides (MA) through co-extraction $(\mathrm{U}+\mathrm{Pu})$ and the recovered $\mathrm{Pu}$ is used for making mixed-oxide (MOX) fuel for the Tier 1 LWR full-core MOX. Following irradiation in the LWR MOX core, the spent fuel is reprocessed to recover the remaining TRU in the MOX fuel after a 5-year cooling period, which is selected for consistency with past calculations. These LWR MOX SNF transuranics and those from the commercial LWRs (only minor actinides) are either combined to make fuel for the Tier 2 fast reactors or the MOX SNF transuranics are separated again into $\mathrm{Pu}$ and MA. In this last scenario the MA from the commercial LWR and from the LWR MOX are combined and assumed to be stored out-of-core, while the remaining $\mathrm{Pu}$ is used to fabricate SFR fuel. The MA from the commercial LWR SNF is assumed to be stored and reprocessed for a total of 7 years. This MA is then further decayed for a period of 11.1 years, which accounts for MOX irradiation, MOX discharge cooling and separation before introduction into the SFR. A schematic of these scenarios is shown below Figure 3-4. A summary of the TRU isotopic vector feeds for the SNF is shown below in Table 3-3. 
Finally, it is important to note that in two scenarios the fast reactors are assumed to be operating in a closed fuel cycle, and thus all TRU is separated and reprocessed into fresh fuel. On the other hand, the two other scenarios assume that both LWRs and fast reactor operate on a plutonium-only fuel cycle, thus there is a net production of MA coming from both systems.

Single Tier Scenario 1: UOX All TRU

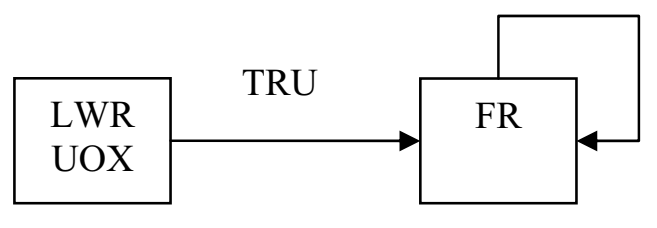

TRU

Single Tier Scenario 2: UOX Pu-only

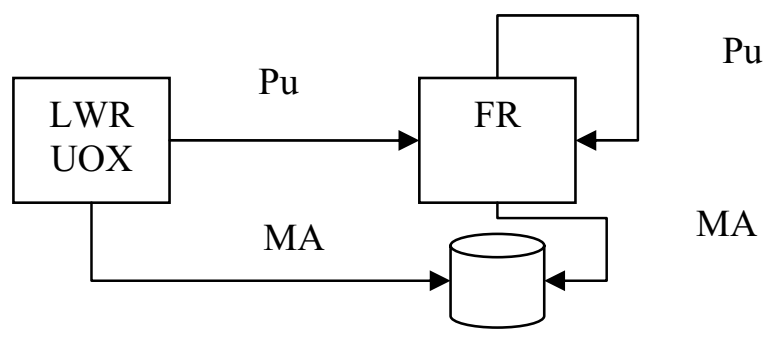

Double Tier Scenario 3: MOX All TRU

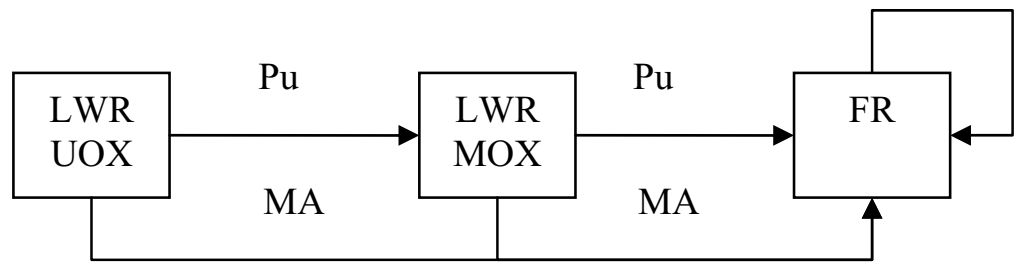

TRU

Double Tier Scenario 4: MOX Pu-only

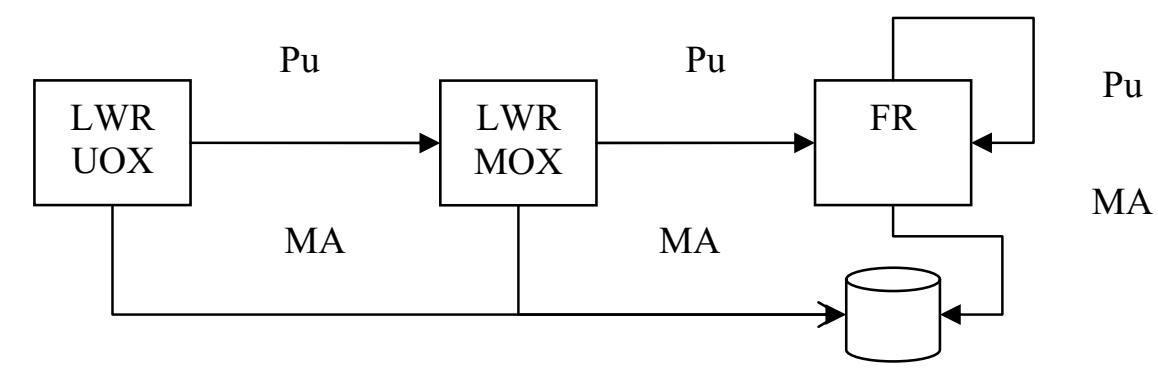

Figure 3-4 Schematic of Fuel Cycle Scenarios 
Table 3-3 External Fast Reactor TRU Isotopic Feeds in Weight Percent for Single and Double Tier Scenarios.

\begin{tabular}{|c|c|c|c|c|}
\hline Isotopes & $\begin{array}{l}\text { Single Tier All } \\
\text { TRU Recycle }\end{array}$ & $\begin{array}{l}\text { Single Tier Pu-only } \\
\text { Recycle }\end{array}$ & $\begin{array}{l}\text { Double Tier All } \\
\text { TRU Recycle One } \\
\text { Pass MOX }\end{array}$ & $\begin{array}{l}\text { Double Tier } \\
\text { Pu-only } \\
\text { Recycle One } \\
\text { Pass MOX }\end{array}$ \\
\hline U-234 & $3.924 \mathrm{E}-04$ & $4.429 \mathrm{E}-04$ & $4.995 \mathrm{E}-04$ & $6.419 \mathrm{E}-04$ \\
\hline U-235 & $2.609 \mathrm{E}-05$ & $2.945 \mathrm{E}-05$ & $1.805 \mathrm{E}-05$ & $2.320 \mathrm{E}-05$ \\
\hline U-236 & $4.700 \mathrm{E}-05$ & $5.300 \mathrm{E}-05$ & $4.995 \mathrm{E}-05$ & $6.337 \mathrm{E}-05$ \\
\hline U-238 & $2.556 \mathrm{E}-07$ & $2.886 \mathrm{E}-07$ & $3.248 \mathrm{E}-07$ & $4.174 \mathrm{E}-07$ \\
\hline $\mathrm{Np}-237$ & $5.539 \mathrm{E}-02$ & $1.738 \mathrm{E}-05$ & $7.587 \mathrm{E}-02$ & $1.921 \mathrm{E}-05$ \\
\hline $\mathrm{Pu}-238$ & $2.505 \mathrm{E}-02$ & $2.828 \mathrm{E}-02$ & $3.189 \mathrm{E}-02$ & $4.098 \mathrm{E}-02$ \\
\hline Pu-239 & $4.613 \mathrm{E}-01$ & $5.207 \mathrm{E}-01$ & $3.193 \mathrm{E}-01$ & $4.103 \mathrm{E}-01$ \\
\hline $\mathrm{Pu}-240$ & $2.264 \mathrm{E}-01$ & $2.551 \mathrm{E}-01$ & $2.410 \mathrm{E}-01$ & $3.050 \mathrm{E}-01$ \\
\hline $\mathrm{Pu}-241$ & $9.357 \mathrm{E}-02$ & $1.056 \mathrm{E}-01$ & $9.082 \mathrm{E}-02$ & $1.167 \mathrm{E}-01$ \\
\hline $\mathrm{Pu}-242$ & 7.004E-02 & $7.906 \mathrm{E}-02$ & $8.902 \mathrm{E}-02$ & $1.144 \mathrm{E}-01$ \\
\hline Am-241 & $4.220 \mathrm{E}-02$ & $1.069 \mathrm{E}-02$ & $9.114 \mathrm{E}-02$ & $1.182 \mathrm{E}-02$ \\
\hline $\begin{array}{l}\text { Am- } \\
242 m\end{array}$ & $9.972 \mathrm{E}-05$ & $0.000 \mathrm{E}+00$ & $6.285 \mathrm{E}-04$ & $0.000 \mathrm{E}+00$ \\
\hline Am-243 & $1.907 \mathrm{E}-02$ & $0.000 \mathrm{E}+00$ & $4.462 \mathrm{E}-02$ & $0.000 \mathrm{E}+00$ \\
\hline $\mathrm{Cm}-242$ & $2.941 \mathrm{E}-07$ & $0.000 \mathrm{E}+00$ & $1.683 \mathrm{E}-06$ & $0.000 \mathrm{E}+00$ \\
\hline $\mathrm{Cm}-243$ & $5.133 \mathrm{E}-05$ & $0.000 \mathrm{E}+00$ & $1.540 \mathrm{E}-04$ & $0.000 \mathrm{E}+00$ \\
\hline $\mathrm{Cm}-244$ & $5.932 \mathrm{E}-03$ & $0.000 \mathrm{E}+00$ & $1.317 \mathrm{E}-02$ & $0.000 \mathrm{E}+00$ \\
\hline $\mathrm{Cm}-245$ & $3.813 \mathrm{E}-04$ & $0.000 \mathrm{E}+00$ & $1.709 \mathrm{E}-03$ & $0.000 \mathrm{E}+00$ \\
\hline $\mathrm{Cm}-246$ & $4.927 \mathrm{E}-05$ & $0.000 \mathrm{E}+00$ & $1.350 \mathrm{E}-04$ & $0.000 \mathrm{E}+00$ \\
\hline $\mathrm{Cm}-247$ & $7.765 \mathrm{E}-07$ & $0.000 \mathrm{E}+00$ & $2.702 \mathrm{E}-06$ & $0.000 \mathrm{E}+00$ \\
\hline $\mathrm{Cm}-248$ & $5.644 \mathrm{E}-08$ & $0.000 \mathrm{E}+00$ & $2.064 \mathrm{E}-07$ & $0.000 \mathrm{E}+00$ \\
\hline Cf-249 & $7.811 \mathrm{E}-10$ & $0.000 \mathrm{E}+00$ & 4.889E-09 & $0.000 \mathrm{E}+00$ \\
\hline Cf- 250 & $2.303 \mathrm{E}-10$ & $0.000 \mathrm{E}+00$ & $5.529 \mathrm{E}-10$ & $0.000 \mathrm{E}+00$ \\
\hline Cf-251 & $1.343 \mathrm{E}-10$ & $0.000 \mathrm{E}+00$ & $4.987 \mathrm{E}-10$ & $0.000 \mathrm{E}+00$ \\
\hline Cf-252 & $1.470 \mathrm{E}-11$ & $0.000 \mathrm{E}+00$ & $1.451 \mathrm{E}-11$ & $0.000 \mathrm{E}+00$ \\
\hline NOTE: & \multicolumn{4}{|c|}{$\begin{array}{l}\text { Because of its short half-life, Am-242 was split between Cm-242 (83\%) and Pu- } \\
242(17 \%)\end{array}$} \\
\hline
\end{tabular}




\section{Analysis Results}

The pertinent results are the mass flow data and associated core data, which have been forwarded to the VISION team via electronic communication. However, for the sake of completeness, core transmutation trends are discussed in this section.

\subsection{Light Water Reactor Fuel Cycle Results}

The isotopes by isotopes mass flow data was provided to the VISION analysis team. The following briefly describes some of the results obtained.

\section{Tier 0 Results}

Table 4-1 summarizes the details of the LWR UOX calculations (Tier 0). The $50 \mathrm{GWd} / \mathrm{MTHM}$ case needs an enrichment of $4.21 \%$, to reach the desired burnup. A higher burnup also means that more MAs are produced. There is also a decrease in the fissile $\mathrm{Pu}$ content if the burnup is increased.

Table 4-1 UOX 50 GWd/MTHM parameters

\begin{tabular}{|l|l|}
\hline UOX fuel burnup (GWd/MTHM) & 50 \\
\hline Uranium enrichment (\%U-235/U) & 4.21 \\
\hline Cycle length (days) & 500 \\
\hline Number of irradiation cycles & 3 \\
\hline Fissile Pu in 5 y cooled SNF $(\%(\mathrm{Pu}-239+\mathrm{Pu}-241) / \mathrm{Pu})$ & $63.72 \%$ \\
\hline Mass of Pu produced in UOX assembly $(\mathrm{kg}$ per assembly) & $5.30 \mathrm{~kg}$ \\
\hline Mass of MA produced in UOX assembly $(\mathrm{kg}$ per assembly) & $0.68 \mathrm{~kg}$ \\
\hline
\end{tabular}

Tier 1 Results

In case of the MOX calculation, a Pu enrichment of $10.6 \%$ was needed to achieve the $50 \mathrm{GWd} / \mathrm{MTHM}$ burnup for a total of $11.34 \mathrm{~kg}$ of Pu per assembly. Table 4-2 summarizes some of the results of the 50 GWd/MTHM case.

Table 4-2 MOX 50 GWd/MTHM parameters

\begin{tabular}{|l|l|}
\hline Heterogeneous MOX fuel burnup (GWd/MTHM) & 50 \\
\hline Number of MOX pins & 264 \\
\hline Recycled uranium enrichment $(\% \mathrm{U}-235 / \mathrm{U})$ & $0.76 \%$ \\
\hline Cycle length (days) & 500 \\
\hline Number of irradiation cycles & 3 \\
\hline Initial Pu content $(\% \mathrm{Pu} / \mathrm{HM})$ & $10.6 \%$ \\
\hline Fissile $\mathrm{Pu}$ in 5 y cooled SNF $(\%(\mathrm{Pu}-239+\mathrm{Pu}-241) / \mathrm{Pu})$ & $53.88 \%$ \\
\hline Mass of Pu destroyed in MOX assembly $(\mathrm{kg}$ per assembly) & $11.34 \mathrm{~kg}$ \\
\hline Mass of MA produced in MOX assembly (kg per assembly) & $3.03 \mathrm{~kg}$ \\
\hline
\end{tabular}




\subsection{Fast Reactor Fuel Cycle Results}

The results from the equilibrium fuel cycle calculations are tabulated in Table 4-3 and Table 4-4 for metal and oxide SFR designs, respectively. Some of the parameters listed include the TRU enrichment for each zone, the fuel residence time in cycles, cycle length, fluence, TRU and MA consumption rate per Effective Full Power Year (EFPY). The general approach taken in this study with regards to the conversion ratio is to differentiate between the 'design' conversion ratio and the 'actual' conversion ratio. The conversion ratio 'design' refers to the SFR designs described in Reference [5]. Varying the external feed will change the 'actual' conversion ratio, which is allowed to 'float'. Thus, an 'actual' conversion ratio is reported for each common design in Table 4-3 and Table 4-4.

As expected, the higher quality plutonium feeds, which contain a larger concentration of fissile $\mathrm{Pu}$, reduce the necessary enrichment relative to the scenarios in which a lower quality plutonium feed is applied. When minor actinide (MA) isotopes, such as americium and curium, displace fissile plutonium in the makeup feed, the fissile worth of the TRU vector is degraded. This is especially evident in the case of single tier Pu-only UOX recycle scenario, as compared to the single-tier 'all TRU' UOX to SFR case. The degradation of the plutonium vector in the two-tier MOX scenario, due to the net consumption of fissile plutonium by the MOX pass, causes the necessary enrichment to increase when compared to the singletier UOX to SFR cases.

The TRU conversion ratio (CR) is also dependent on the fast reactor fresh fuel makeup feed. Higher fuel enrichment requires higher TRU loading on a mass basis, which decreases the TRU CR due to an overall reduction of U-238 in the core. This is especially noticeable in the low CR cases, since a larger fraction of the mass is made up of TRU isotopes. Differences in the TRU and MA consumption rate, in terms of $\mathrm{kg}$ of TRU per EFPY, can vary greatly depending on whether the MA is being reprocessed back into the fresh fuel or assumed to be stored permanently. 
Table 4-3 Equilibrium Fuel Cycle Results for Metal SFR Design for Multiple Scenarios.

\begin{tabular}{|c|c|c|c|c|c|c|c|c|c|}
\hline & & \multicolumn{4}{|c|}{$\mathrm{CR}=0.50$ Design } & \multicolumn{4}{|c|}{$\mathrm{CR}=0.75$ Design } \\
\hline \multicolumn{2}{|c|}{ Scenario } & UOX TRU & UOX Pu & MOX TRU & $\mathrm{MOXPu}$ & UOX TRU & UOX Pu & MOX TRU & $\mathrm{MOXPu}$ \\
\hline \multicolumn{2}{|c|}{ Actual Conversion Ratio } & 0.52 & 0.55 & 0.49 & 0.53 & 0.77 & 0.79 & 0.75 & 0.78 \\
\hline \multirow{3}{*}{$\begin{array}{c}\text { Charge } \\
\text { Enrichment, } \\
\text { TRU/HM (v/f) }\end{array}$} & IC & $27.0 \%$ & $25.3 \%$ & $29.4 \%$ & $27.1 \%$ & $15.9 \%$ & $15.1 \%$ & $16.8 \%$ & $15.7 \%$ \\
\hline & MC & $33.7 \%$ & $31.6 \%$ & $36.7 \%$ & $33.9 \%$ & $19.8 \%$ & $18.9 \%$ & $20.9 \%$ & $19.6 \%$ \\
\hline & $\mathrm{OC}$ & $40.4 \%$ & $37.9 \%$ & $44.1 \%$ & $40.6 \%$ & $23.8 \%$ & $22.7 \%$ & $25.1 \%$ & $23.6 \%$ \\
\hline \multirow{3}{*}{$\begin{array}{l}\text { Fuel residence } \\
\text { time, cycles }\end{array}$} & IC & 6 & 6 & 6 & 6 & 6 & 6 & 6 & 6 \\
\hline & MC & 6 & 6 & 6 & 6 & 6 & 6 & 6 & 6 \\
\hline & OC & 7 & 7 & 7 & 7 & 6.5 & 6.5 & 6.5 & 6.5 \\
\hline Burnup (MWd/kg) & $\begin{array}{l}\text { Ave. } \\
\text { Driver }\end{array}$ & 128.9 & 129.8 & 127.2 & 129.6 & 98.1 & 97.9 & 98.1 & 97.8 \\
\hline \multirow{3}{*}{$\begin{array}{c}\text { Peak Fast } \\
\text { Fluence, } 10^{\star \star} 23 \\
\text { n/cm } 2 \text { (cm } 2\end{array}$} & IC & 3.95 & 3.96 & 3.95 & 3.95 & 3.82 & 3.80 & 3.84 & 3.81 \\
\hline & MC & 3.90 & 3.93 & 3.84 & 3.91 & 3.95 & 3.95 & 3.95 & 3.95 \\
\hline & OC & 3.66 & 3.71 & 3.56 & 3.69 & 3.93 & 3.93 & 3.91 & 3.93 \\
\hline \multirow{3}{*}{ Maximum DPA } & IC & 181 & 180 & 181 & 180 & 170 & 169 & 172 & 169 \\
\hline & MC & 188 & 188 & 186 & 188 & 187 & 186 & 188 & 186 \\
\hline & OC & 171 & 172 & 166 & 171 & 191 & 191 & 190 & 190 \\
\hline \multicolumn{2}{|c|}{ HM loading, $\mathrm{kg}$} & 9,303 & 9,347 & 9,233 & 9,348 & 13,192 & 13,241 & 13,117 & 13,241 \\
\hline \multicolumn{2}{|c|}{ TRU loading, $\mathrm{kg}$} & 3,017 & 2,837 & 3,272 & 3,051 & 2,776 & 2,658 & 2,912 & 2,764 \\
\hline \multicolumn{2}{|c|}{ Fissile Pu loading, kg } & 1,289 & 1,397 & 1,177 & 1,338 & 1,482 & 1,550 & 1,423 & 1,517 \\
\hline \multicolumn{2}{|c|}{ Cycle length, EFPD } & 212 & 215 & 208 & 214 & 225 & 225 & 224 & 225 \\
\hline \multicolumn{2}{|c|}{$\begin{array}{c}\text { TRU Consumption Rate, } \\
\text { kg/EFPY }\end{array}$} & 165.8 & 155.6 & 177.2 & 163.2 & 74.0 & 66.8 & 80.3 & 70.0 \\
\hline \multicolumn{2}{|c|}{$\begin{array}{c}\text { MA Consumption Rate, } \\
\text { kg/EFPY }\end{array}$} & 20.7 & -20.9 & 39.6 & -26.4 & 9.7 & -14.0 & 18.4 & -16.6 \\
\hline \multicolumn{2}{|c|}{ TRU Charge, kg/EFPY } & 905 & 843 & 998 & 906 & 754 & 720 & 795 & 749 \\
\hline \multicolumn{2}{|c|}{ HM Charge, kg/EFPY } & 2,745 & 2,729 & 2,779 & 2,732 & 3,609 & 3,618 & 3,606 & 3,620 \\
\hline
\end{tabular}


Table 4-4 Equilibrium Fuel Cycle Results for Oxide SFR Design for Multiple Scenarios.

\begin{tabular}{|c|c|c|c|c|c|c|c|c|c|}
\hline & & \multicolumn{4}{|c|}{$C R=0.50$ Design } & \multicolumn{4}{|c|}{$\mathrm{CR}=0.75$ Design } \\
\hline \multicolumn{2}{|c|}{ Scenario } & UOX TRU & UOX Pu & MOX TRU & $\mathrm{MOX} \mathrm{Pu}$ & UOX TRU & UOX Pu & MOX TRU & $\mathrm{MOXPu}$ \\
\hline \multicolumn{2}{|c|}{ Actual Conversion Ratio } & 0.51 & 0.54 & 0.49 & 0.51 & 0.76 & 0.78 & 0.76 & 0.77 \\
\hline \multirow{3}{*}{$\begin{array}{c}\text { Charge } \\
\text { Enrichment, } \\
\text { TRU/HM (v/f) }\end{array}$} & IC & $32.6 \%$ & $30.8 \%$ & $34.6 \%$ & $33.1 \%$ & $21.3 \%$ & $20.6 \%$ & $21.9 \%$ & $21.3 \%$ \\
\hline & MC & $40.8 \%$ & $38.5 \%$ & $43.3 \%$ & $41.4 \%$ & $26.6 \%$ & $25.7 \%$ & $27.4 \%$ & $26.6 \%$ \\
\hline & OC & $48.9 \%$ & $46.2 \%$ & $52.0 \%$ & $49.7 \%$ & $31.9 \%$ & $30.8 \%$ & $32.9 \%$ & $31.9 \%$ \\
\hline \multirow{3}{*}{$\begin{array}{l}\text { Fuel residence } \\
\text { time, cycles }\end{array}$} & IC & 6 & 6 & 6 & 6 & 6 & 6 & 6 & 6 \\
\hline & MC & 6 & 6 & 6 & 6 & 6 & 6 & 6 & 6 \\
\hline & OC & 7 & 7 & 7 & 7 & 7 & 7 & 7 & 7 \\
\hline Burnup (MWd/kg) & $\begin{array}{l}\text { Ave. } \\
\text { Driver }\end{array}$ & 165.4 & 166.1 & 160.6 & 166.7 & 127.7 & 131.1 & 124.1 & 129.2 \\
\hline \multirow{3}{*}{$\begin{array}{c}\text { Peak Fast } \\
\text { Fluence, } 10^{* \star} 23 \\
\text { n/cm }{ }^{\star \star} 2\end{array}$} & IC & 3.92 & 3.87 & 3.95 & 3.88 & 3.95 & 3.95 & 3.96 & 3.95 \\
\hline & MC & 3.85 & 3.83 & 3.77 & 3.84 & 3.78 & 3.85 & 3.69 & 3.80 \\
\hline & OC & 3.95 & 3.95 & 3.82 & 3.95 & 3.80 & 3.90 & 3.66 & 3.83 \\
\hline \multirow{3}{*}{ Maximum DPA } & IC & 194 & 190 & 195 & 191 & 196 & 196 & 196 & 196 \\
\hline & MC & 199 & 197 & 196 & 198 & 198 & 200 & 194 & 199 \\
\hline & $\mathrm{OC}$ & 198 & 197 & 192 & 197 & 194 & 199 & 188 & 195 \\
\hline \multicolumn{2}{|c|}{ HM loading, $\mathrm{kg}$} & 10,916 & 10,904 & 10,957 & 10,902 & 15,270 & 15,239 & 15,307 & 15,255 \\
\hline \multicolumn{2}{|c|}{ TRU loading, kg } & 4,147 & 3,908 & 4,435 & 4,211 & 3,905 & 3,766 & 4,031 & 3,903 \\
\hline \multicolumn{2}{|c|}{ Fissile Pu loading, $\mathrm{kg}$} & 1,679 & 1,830 & 1,533 & 1,752 & 1,935 & 2,041 & 1,860 & 1,991 \\
\hline \multicolumn{2}{|c|}{ Cycle length, EFPD } & 324 & 325 & 316 & 326 & 344 & 353 & 335 & 348 \\
\hline \multicolumn{2}{|c|}{$\begin{array}{c}\text { TRU Consumption Rate, } \\
\text { kg/EFPY }\end{array}$} & 173.5 & 163.3 & 181.0 & 173.0 & 76.6 & 71.8 & 78.3 & 74.3 \\
\hline \multicolumn{2}{|c|}{$\begin{array}{c}\text { MA Consumption Rate, } \\
\text { kg/EFPY }\end{array}$} & 21.8 & -26.7 & 40.8 & -33.4 & 10.1 & -18.9 & 18.2 & -22.1 \\
\hline \multicolumn{2}{|c|}{ TRU Charge, kg/EFPY } & 822 & 775 & 898 & 830 & 692 & 652 & 732 & 684 \\
\hline \multicolumn{2}{|c|}{ HM Charge, kg/EFPY } & 2,143 & 2,136 & 2,203 & 2,128 & 2,765 & 2,698 & 2,842 & 2,735 \\
\hline
\end{tabular}


The fast reactor fuel cycle results presented above are overall summaries of the transmutation performance of the system at equilibrium. Since in the plutonium-only fuel cycle the MA produced by the fast reactor during a cycle is discharged out of the fast reactor fuel cycle indefinitely, there is a net generation of MAs that comes from the LWR separation strategy and SFR reprocessing. Thus, ignoring separation losses, MAs from both LWR and SFR SNF are accumulated in the two scenarios where they are not recycled in the fast reactor (Scenario 2 and 4 ).

\subsection{Reactor Charge and Discharge Results}

The equilibrium charge mass data for all the fuel cycle scenarios were processed through internal tools and decayed using ORIGEN-S in order to calculate the decay heat, gamma heating, and neutron emission. The results are tabulated along with previous calculations of thermal LWR IMF and MOX charge neutron emission, gamma energy, and decay heat.

\subsubsection{Decay Heat Results}

The decay heat data for the reactor equilibrium charge in the four scenarios is compared to thermal IMF and MOX recycling in Figure 4-1. As expected, the decay heat per kg of TRU is similar between metal and oxide fuel. On the other hand, it is higher in the $\mathrm{CR}=0.50$ cases due to the higher concentration of TRU, as compared to the $\mathrm{CR}=0.75$ scenarios. In addition the decay heat strongly depends on whether all the LWR and fast reactor SNF MAs are recycled into the fresh feed. This is due to the fact that excess MA from recovered LWR SNF, together with MA produced in the fast reactor, are assumed to be indefinitely separated and stored permanently in the plutonium-only fuel cycles, thus decreasing the equilibrium charge fuel decay heat. On the other hand, this fuel cycle generates a net amount of MA from the separated UOX, MOX, and the fast reactors discharge. The decay heat is also observed to be higher in the double tier MOX TRU compared to the single tier UOX TRU due to the MAs produced by the single MOX pass.

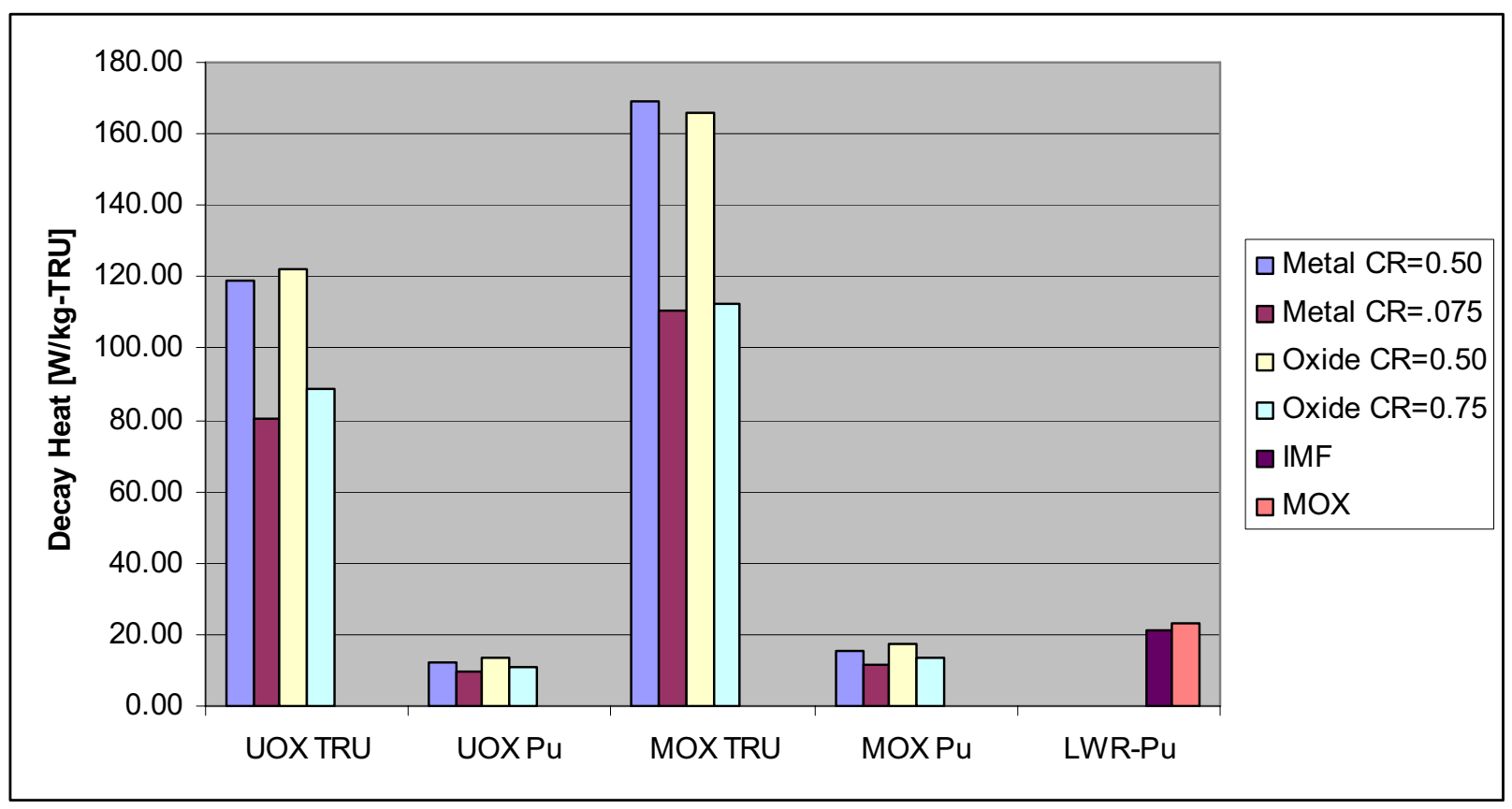

Figure 4-1 Charge Decay Heat per kg of TRU For SFR and Thermal Recycling with Multiple Scenarios. 
An equally important measure of the decay heat is the decay heat per assembly at discharge. Such data has been tabulated below in Table 4-5 and Table 4-6. It is evident from the table below that, on a per assembly basis, the oxide fuel discharge decay heat is higher than metal fuel discharge decay heat. Although the mass density of oxide fuel is less than the metal fuel density, the oxide fuel assemblies are larger (35\% taller) and contain a greater volume fraction of fuel $(30.22 \%$ versus $22.08 \%)$ than their metal counterparts. Following to the trends found in the decay heat per mass of TRU, the scenarios in which the MA is excluded from being reprocessed into fresh fuel lower the decay heat per subassembly.

Table 4-5 Charge and Discharge Decay Heat for Metal CR=0.50 and 0.75 SFR Design for Multiple Scenarios.

\begin{tabular}{|c|c|c|c|c|c|c|c|c|c|}
\hline & & \multicolumn{8}{|c|}{ Maximum Decay Heat (Watts/Subassembly) } \\
\hline & & \multirow{2}{*}{$\begin{array}{c}\text { Charge } \\
0.00 \\
\end{array}$} & \multicolumn{7}{|c|}{ Years Decayed from Discharge } \\
\hline & Scenarios & & 0.00 & 0.01 & 1.00 & 3.00 & 5.00 & 15.00 & 20.00 \\
\hline \multirow{4}{*}{ 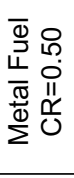 } & UOX TRU & 419 & 7091 & 5253 & 890 & 415 & 324 & 235 & 210 \\
\hline & UOX Pu & 41 & 6405 & 4561 & 552 & 185 & 111 & 77 & 73 \\
\hline & MOX TRU & 642 & 7487 & 5668 & 1107 & 561 & 459 & 337 & 299 \\
\hline & $\mathrm{MOX} \mathrm{Pu}$ & 55 & 6465 & 4611 & 577 & 202 & 127 & 90 & 86 \\
\hline \multirow{4}{*}{ 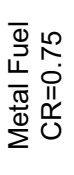 } & UOX TRU & 280 & 7813 & 5683 & 815 & 339 & 245 & 175 & 158 \\
\hline & UOX Pu & 31 & 7311 & 5188 & 590 & 189 & 107 & 71 & 67 \\
\hline & MOX TRU & 403 & 8054 & 5925 & 937 & 421 & 321 & 232 & 208 \\
\hline & MOX Pu & 39 & 7342 & 5214 & 603 & 198 & 115 & 78 & 74 \\
\hline
\end{tabular}

Table 4-6 Charge and Discharge Decay Heat for Oxide CR=0.50 and 0.75 SFR Design for Multiple Scenarios.

\begin{tabular}{|c|c|c|c|c|c|c|c|c|c|}
\hline & \multirow[b]{3}{*}{ Scenarios } & \multicolumn{8}{|c|}{ Maximum Decay Heat (Watts/Subassembly) } \\
\hline & & \multirow{2}{*}{$\begin{array}{c}\text { Charge } \\
0.00 \\
\end{array}$} & \multicolumn{7}{|c|}{ Years Decayed from Discharge } \\
\hline & & & 0.00 & 0.01 & 1.00 & 3.00 & 5.00 & 15.00 & 20.00 \\
\hline \multirow{4}{*}{ 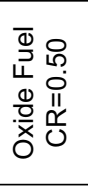 } & UOX TRU & 547 & 9770 & 7187 & 1205 & 570 & 443 & 319 & 285 \\
\hline & UOX Pu & 104 & 9829 & 7039 & 912 & 329 & 212 & 148 & 137 \\
\hline & MOX TRU & 772 & 11407 & 8452 & 1507 & 745 & 592 & 426 & 378 \\
\hline & $\mathrm{MOX} \mathrm{Pu}$ & 143 & 10108 & 7260 & 984 & 374 & 252 & 179 & 165 \\
\hline \multirow{4}{*}{ 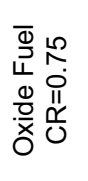 } & UOX TRU & 355 & 9870 & 7161 & 1039 & 441 & 321 & 228 & 206 \\
\hline & UOX Pu & 73 & 10406 & 7419 & 894 & 303 & 183 & 123 & 115 \\
\hline & MOX TRU & 471 & 10726 & 7829 & 1204 & 538 & 405 & 290 & 261 \\
\hline & $\mathrm{MOX} \mathrm{Pu}$ & 92 & 10409 & 7431 & 918 & 322 & 201 & 138 & 129 \\
\hline
\end{tabular}




\subsubsection{Gamma Heating Results}

The gamma heating produced by fast reactor recycled fuel is compared in Figure 4-2. The trends are similar to the decay heat data in that the additional TRU that is recycled from LWR SNF causes the gamma heating to increase. Additionally, the gamma heating released by the charge fuel decreases as the TRU CR is increased from 0.50 to 0.75 . This is caused by the net lower concentration of TRU on a per $\mathrm{kg}$ basis. The gamma heating is also observed to be higher for the double tier MOX TRU case compared to the single tier UOX TRU. This is due to the net production of MA that the single MOX pass produces.

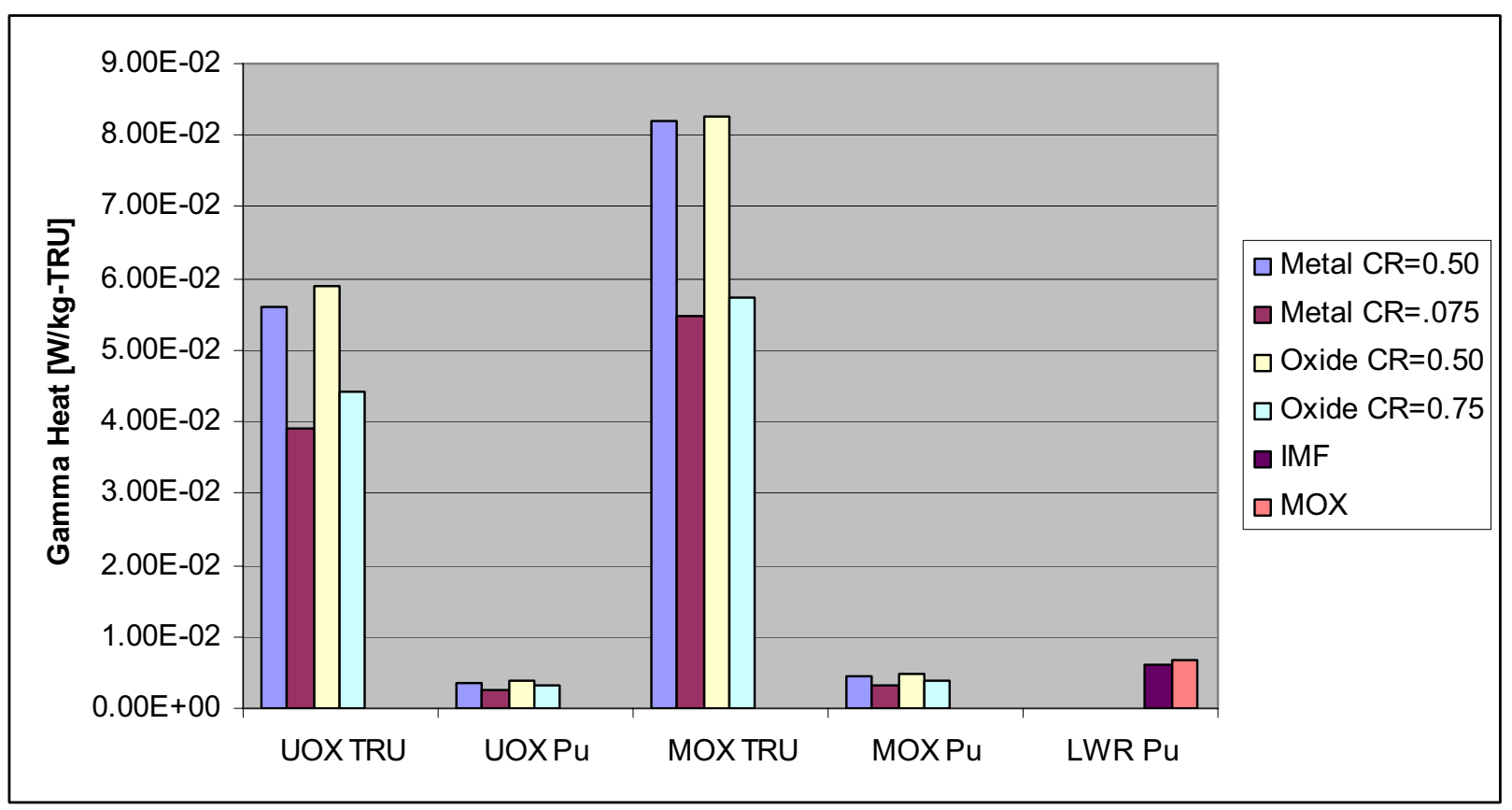

Figure 4-2 Charge Gamma Heating for SFR and Thermal Recycling with Multiple Scenarios.

\subsubsection{Neutron Emmission Results}

The neutron emission rate is shown below for all four scenarios in Figure 4-3. The neutron emission greatly increases depending on the recycling strategy. For example, for single and double tier scenarios that utilize the plutonium-only fuel cycle, the neutron emission is at least two orders of magnitude less than the homogeneous all TRU scenarios. In the case of $\mathrm{CR}=0.50$ and 0.75 , the decrease in neutron emission is not as dramatic as in the decay heat and gamma heating parameters. 


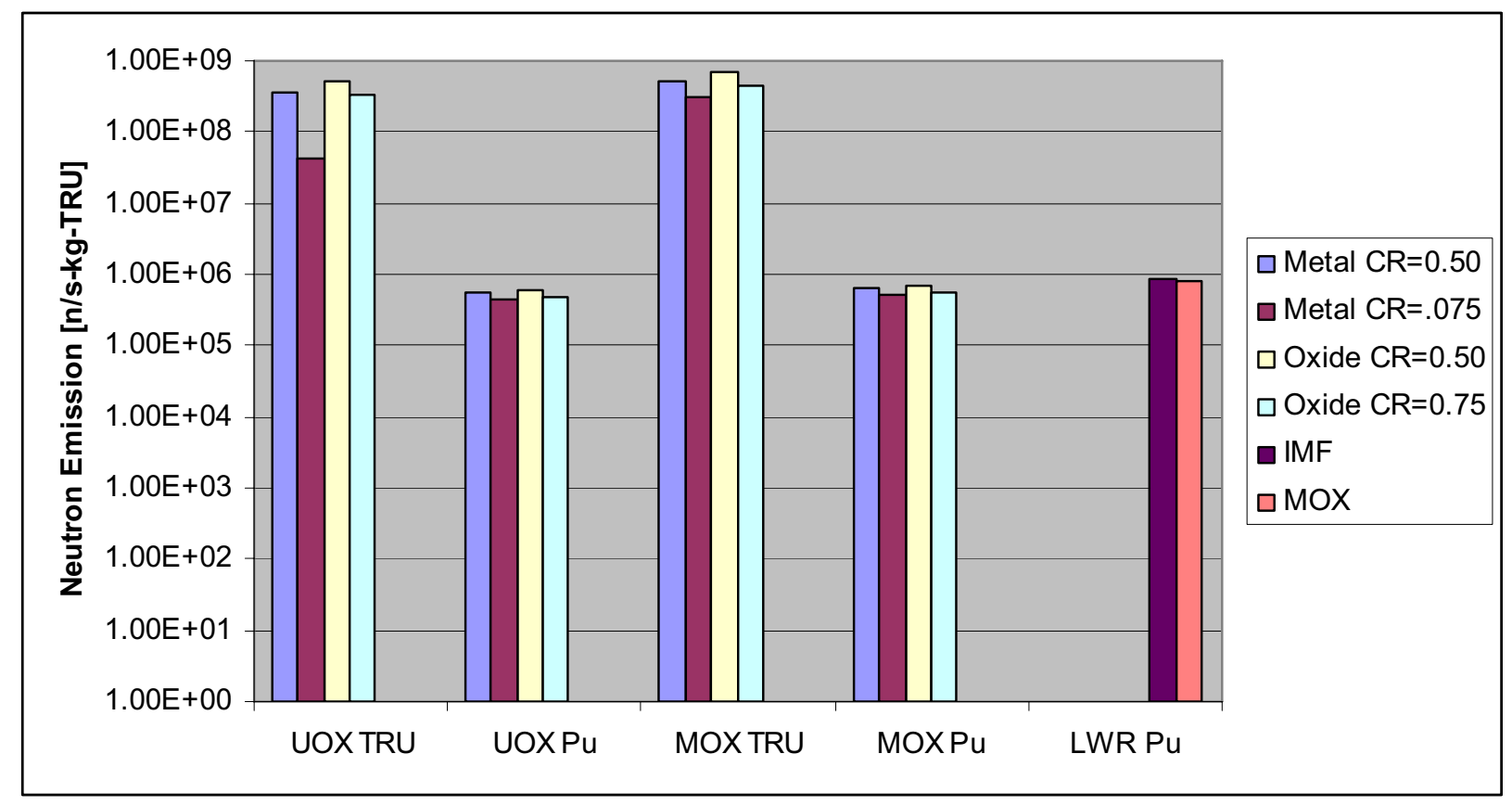

Figure 4-3 Charge Neutron Emissions for SFR and Thermal Recycling with Multiple Scenarios. 


\section{Conclusions and Future Work}

The 1000 MWth Sodium Fast Reactor (SFR)-type design was used as the baseline in this study. Two transuranic conversion ratios (TRU CR) were explored, 0.50 and 0.75 , along with metal and oxide fast reactor fuel options. The purpose of these scenarios analyses was to provide the System Analysis group with VISION isotope recipes of single and double tier reprocessing options. The VISION code is a computer based simulation model that allows the performance of dynamic simulations of fuel cycles to quantify infrastructure requirements and identify key trade-offs between alternatives. Since direct neutronic calculations are not performed within the model, 'recipes' for different reactor types must be provided by the fuel cycle analysis group in the form of VISION-formatted isotope data. These scenarios involve the option of either separating the plutonium from the recycled TRU or to keep it together with the minor actinides. This report outlines the results of these scenarios from a transmutation analysis perspective. Further considerations, such as economics, proliferation 'attractiveness', fuel handling capabilities, etc. are outside the scope of this work.

General observations on the effects of the scenarios studied on the transmutation performance of the system are as follows: the necessary enrichment for metal and oxide $\mathrm{CR}=0.50$ and 0.75 increases as the fuel makeup feed is degraded from its initial fissile worth. This degradation occurs in the scenarios where the MAs from either the LWR or fast reactor SNF are reprocessed into fresh fuel together with the plutonium. Another effect that degrades the reactivity worth of an isotopic vector is the addition of a tier 1 MOX pass, which causes a net production of MAs. Lower fast reactor equilibrium enrichments are achieved when the MAs are separated and assumed to be permanently taken out of the fuel cycle. These trends are seen in both the metal and oxide $\mathrm{CR}=0.50$ and 0.75 cases.

It was also generally observed in all scenarios that the removal of MAs after discharge from either LWR or fast reactor SNF decreases the decay heat, gamma heating, and neutron emission. Another observation is the net increase in all three quantities when a double tier approach is taken due to the net increase in MAs at MOX discharge. Finally, the continuous removal from the MAs at any stage within the fuel cycle causes an unavoidable net production regardless of reactor type. This causes the next reactor-tier in the fuel cycle to have a larger MA burden or necessitate a non-reactor storage solution outside the system.

Future work could focus on quantifying the effects of a multi-tier strategy where multiple thermal recycling is applied to the discharge LWR SNF. Such strategies would further degrade the isotopic vector to a point where a large fraction of the discharged fuel used as makeup feed to the fast reactor is composed of MAs. 


\section{References}

1. T. A. TAIWO, E. A. HOFFMAN, and T. K. KIM, "Core Transmutation Data for Double-Tier Scenario Studies - Scenario 2,” Intra-Laboratory Memo, Argonne National Laboratory (2007).

2. A. E. DUBBERLEY, K. YOSHIDA, C. E. BOARMAN, and T. WU, "SuperPRISM Oxide and Metal Fuel Core Designs," Proc. of ICONE 8, $8^{\text {th }}$ International Conference on Nuclear Engineering (2000).

3. R. N. HILL, D. C. WADE, E. K. FUJITA, and H. KHALIL, "Physics Studies of Higher Actinide Consumption in an LMR," Proc. Int. Conf. on the Physics of Reactors, Marseille, France, p.I-83, April 23-27 (1990).

4. R. N. HILL, D. C. WADE, J. R. LIAW, and E. K. FUJITA, "Physics Studies of Weapons Plutonium Disposition in the Integral Fast Reactor Closed Fuel Cycle," Nuclear Science and Engineering, 121, 17 (1995).

5. E. A. HOFFMAN, W. S. YANG, and R. N. HILL, "Preliminary Core Design Studies for the Advanced Burner Reactor over a Wide Range of Conversion Ratios," Argonne National Laboratory, ANL-AFCI-177 (2006).

6. SCALE: A Modular Code System for Performing Standardized Computer Analyses for Licensing Evaluation, ORNL/TM-2005/39, Version 5.1, Vols. I-III, November 2006. Available from Radiation Safety Information Computational Center at Oak Ridge National Laboratory as C00732.

7. TRITON: A Two-Dimensional Transport and Depletion Module for Characterization of Spent Nuclear Fuel, ORNL/TM-2005/39, Revision 5.1, Vol. I, Book 3, Sect. T1, November 2006. Available from Radiation Safety Information Computational Center at Oak Ridge National Laboratory as C00-732.

8. ORIGEN-S: Scale System Module to Calculate Fuel Depletion, Actinide Transmutation, Fission Product Buildup and Decay, and Associated Radiation Source Terms, ORNL/TM-2005/39, Revision 5.1, Vol. II, Book 1, Sect. F7, November 2006. Available from Radiation Safety Information Computational Center at Oak Ridge National Laboratory as C00-732.

9. H. HENRYSON II, B. J. TOPPEL, and C. G. STENBERG, "MC'2-2: A Code to Calculate Fast Neutron Spectra and Multi-Group Cross-Sections." ANL-8144, Argonne National Laboratory (1976).

10. B. J. Toppel, "A User's Guide to the REBUS-3 Fuel Cycle Analysis Capability," ANL-83-2, Argonne National Laboratory (1983). 
11. R. M. FERRER, M. ASGARI, S. BAYS, and B. FORGET, "Fast Reactor Alternative Studies: Effects of Transuranic Groupings on Metal and Oxide Sodium Fast Reactor Designs," Idaho National Laboratory, INL-EXT-07-13236 (2007). 